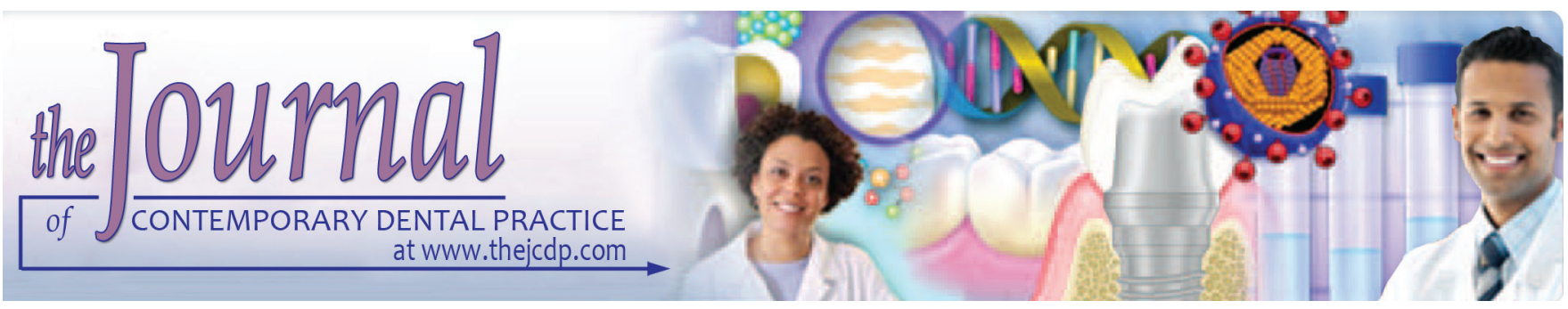

\title{
Assessment of Various Nutritional Parameters in Geriatric Patients Who underwent Different Prosthodontic Treatments
}

\author{
${ }^{1}$ Sarita Aneja, ${ }^{2}$ Vasanti A Jeergal, ${ }^{3}$ Alpesh Patel, ${ }^{4}$ Atul Bhardwaj, ${ }^{5}$ Nikunj Patel, ${ }^{6}$ Vidhi Shah
}

\begin{abstract}
Background: Some relation exists between oral and general health with progressive aging. Certain risk factors are common between oral and systemic diseases. Absence of teeth also affects the oral health by altering the quality of life. Hence, the nutritional changes occurring in elderly patients following prosthodontic rehabilitation are evaluated.
\end{abstract}

Materials and methods: A total of 250 patients who underwent prosthodontic treatment for missing teeth were included for the study. Twice measurement of nutritional parameters was done: Initially at the time of diagnosis and then 5 months following commencement of the prosthodontic treatment. Dental analysis, evaluation of the diet, anthropometric assessment, and analysis of serum biochemical values were done in all the patients and tabulated records were maintained. Independent Student's t test and Tukey's test were done to assess the level of significance.

Results: A total of 250 patients were included for the study. The complete denture (CD) group showed the highest alteration in the mean values of the nutritional parameters followed by the removable partial denture group. A significant change was seen in the body mass index, protein, carbohydrate, and iron levels

${ }^{1}$ Department of Prosthodontics, Maharaja Ganga Singh Dental College and Research Centre, Shri Ganganagar, Rajasthan India

${ }^{2}$ Department of General Medicine, Srinivas Institute of Medical Science and Research Centre, Mangaluru, Karnataka, India

${ }^{3}$ Department of Oral Pathology, Goenka Research Institute of Dental Science, Gandhinagar, Gujarat, India

${ }^{4}$ Department of Prosthodontic Dental Sciences, College of Dentistry, Majmaah University, Saudi Arabia

${ }^{5}$ Department of Conservative and Endodontics, Narsinhbhai Patel Dental College and Hospital, Visnagar, Gujarat, India

${ }^{6}$ Department of Conservative and Endodontics, Narsinhbhai Patel Dental College and Hospital, Visnagar, Gujarat, India

Corresponding Author: Sarita Aneja, Reader, Department of Prosthodontics, Maharaja Ganga Singh Dental College and Research Centre, Shri Ganganagar, Rajasthan, India, Phone: +919414509596, e-mail: drsaritaaneja@gmail.com among the different patients who were grouped based on the mode of treatment modality. The CD group showed significantly higher mean change in carbohydrates value compared with mean change in patients receiving fixed treatment.

Conclusion: Both nutrition and diet form an integral part of the prosthodontic treatment to maintain the health of elderly population.

Clinical significance: With the advancement in the level of edentulism, rehabilitation by prosthetic treatment has become progressively important to restore and improve dietary parameters.

Keywords: Denture, Edentulous, Prosthodontic treatment.

How to cite this article: Aneja S, Jeergal VA, Patel A, Bhardwaj A, Patel N, Shah V. Assessment of Various Nutritional Parameters in Geriatric Patients Who underwent Different Prosthodontic Treatments. J Contemp Dent Pract 2016;17(5):408-413.

Source of support: Nil

Conflict of interest: None

\section{INTRODUCTION}

As the age progresses, it is a much accepted fact that there exists some relationship between health of oral tissues and general health. ${ }^{1}$ By having a review on the data published in the literature, it is much evident that both oral and systemic diseases have in common certain risk factors, such as smoking, glucose control, etc. ${ }^{2,3}$ Absence of teeth due to any reason affects the health of oral tissues and the body in a huge way by altering the quality of life along with nutrition and food habits. ${ }^{4}$ As far as dental implants are concerned, reports of initial analysis involving both functional and esthetic components of life have been proved to be in favor of both patients and the dentists. ${ }^{5}$ Therefore, prosthodontic treatment should also include evaluation of patient's nutritional history and diet as its primary goal. ${ }^{6}$ Hence, this study was planned to evaluate the dietary and nutritional changes in elderly patients following rehabilitation by prosthodontic treatment. 


\section{MATERIALS AND METHODS}

The study was conducted in 2014-2015 with a total of 250 patients reporting to the prosthodontic outpatient department of the hospital for the treatment of missing teeth. Patients were preinformed about the study and a written consent was obtained from each of them. All the parameters were measured twice: Initially at the time of diagnosis and then 5 months following commencement of the prosthodontic treatment. Only those patients who fulfilled the following inclusion criteria were included in the study:

- Patients above 60 years of age (to avoid biasness in the results of the study). ${ }^{7}$

- Patients without any history of systemic illness, known as drug allergy.

- Patients without any medical history of limitation of any extremity or functional limitation.

- Patients without any psychological disorder.

- Patients who were not financially above the poverty line. $^{8}$

- Patients without any history and present habit of tobacco chewing or smoking, alcohol consuming, and any other known addictive habit according to the World Health Organization criteria. ${ }^{9,10}$

After selecting the patients for the study, the following investigations were performed: Dental analysis, evaluation of the diet, anthropometric assessment, and analysis of serum biochemical values. Examination of dentition involved assessment of distribution of teeth (distal extension case or not), number of missing teeth in the edentulous area, and the type of prosthetic treatment recommended. While planning for the treatment, third molars were not included. Accordingly, patients were divided into following groups: CE: Completely edentulous and PE: Partially edentulous. The PE group were further categorized into three groups; group 1: Less than 8 missing teeth, group 2: 8 to 18 missing teeth, and group 3: More than 18 missing teeth. Patients were also divided depending on the type of prosthetic treatment required: $\mathrm{CD}$ : Complete denture, RPD: Removable partial denture, and FPD: Fixed partial denture. The RPD group patients were further divided into two groups: Distal extension denture prosthesis (DEDP) (Kennedy type I, II) and tooth-supported denture prosthesis (TSDP) (Kennedy type III, IV). Patients who required implants in the treatment protocol were excluded from the study. Posttreatment, daily dietary and nutritional records of the patients were maintained. Nutritional status of the patients was measured and all the collected data were tabulated in terms of energy and nutritional values, which include fats, proteins, carbohydrates, kilocalories consumed, calcium, vitamin A, B, and C. ${ }^{11-15}$ Measurement of the anthropometric values was done by evaluating the body mass index (BMI). ${ }^{7}$ For biochemical assessment, $10 \mathrm{ml}$ of fasting blood samples was taken from all the patients at initial assessment time and after 5 months. For evaluation of malnutrition, serum albumin and cholesterol were used as biomarkers. Cholesterol oxidase method and bromocresol green dye binding method were used for the assessment of total cholesterol and albumin levels. ${ }^{16,17}$ All the tests were done again after 5 months following prosthodontic treatment. All the results were evaluated using Statistical Package for the Social Sciences software. Independent Student's t test and Tukey's test were used to assess the level of significance.

\section{RESULTS}

A total of 250 patients were included for the study. Table 1 shows the dental status of the patients. Table 2 and Graph 1 highlight the mean change in variables from baseline to 5 months measured in different prosthetic groups. The $\mathrm{CD}$ group showed the highest alteration in the mean values of the nutritional parameters followed by the RPD group, as shown in Table 2. Table 3 highlights the comparison of initial mean value and mean value after 5 months in all the nutritional parameters between different groups. Although nonsignificant $(p>0.05)$ difference was observed while comparing mean change in albumin, cholesterol, calcium, and vitamins groups; other remaining variables showed statistically significant variation. The $C D$ group showed significantly higher mean change in carbohydrate value compared with mean change in patients receiving fixed treatment. While comparing the mean change at baseline and 5 months after the completion of the treatment in the different missing teeth groups, out of all nutritional parameters, proteins and vitamin B showed statistically significant variation, as depicted in Table 4. Tables 5 and 6 show the mean changes from baseline to 5 months measured in variables when compared between completely and partially edentulous patients and between removable prosthesis and fixed prosthesis respectively.

Table 1: Dental status of all the patients

\begin{tabular}{lll}
\hline Variable & & $n=250(\%)$ \\
\hline Dentition status & Completely edentulous & $120(48)$ \\
& Partially edentulous & $130(52)$ \\
Prosthesis & CD & $120(48)$ \\
recommended & FPD & $60(24)$ \\
& DEDP & $40(16)$ \\
Missing teeth & TSDP & $30(12)$ \\
& Group 1 & $57(22.8)$ \\
& Group 2 & $38(15.2)$ \\
Prosthesis type & Group 3 & $35(14)$ \\
& Removable & $190(76)$ \\
& (CD+DEDP+TSDP) \\
& Fixed (FPD) & $60(24)$ \\
\hline
\end{tabular}


Table 2: Mean change in variables from baseline to 5 months measured in different prosthetic groups

\begin{tabular}{llllll}
\hline Variable & & $C D(120)$ & $D E D P(40)$ & $T S D P(30)$ & $F P D(60)$ \\
\hline Anthropometric variables & Weight $(\mathrm{kg})$ & $1.68 \pm 1.23$ & $0.47 \pm 1.64$ & $0.53 \pm 0.89$ & $0.41 \pm 1.19$ \\
& BMI $\left(\mathrm{kg} / \mathrm{m}^{2}\right)$ & $0.88 \pm 0.45$ & $0.25 \pm 0.59$ & $0.31 \pm 0.48$ & $0.21 \pm 0.51$ \\
Biochemical variables & Serum albumin $(\mathrm{g} / \mathrm{dl})$ & $0.71 \pm 0.35$ & $0.09 \pm 0.15$ & $0.02 \pm 0.45$ & $0.09 \pm 0.41$ \\
& Serum cholesterol $(\mathrm{mg} / \mathrm{dl})$ & $1.90 \pm 7.75$ & $3.29 \pm 7.81$ & $2.67 \pm 7.02$ & $0.52 \pm 11.31$ \\
Nutrients & Proteins $(\mathrm{g})$ & $25.43 \pm 6.12$ & $18.96 \pm 6.45$ & $19.01 \pm 7.82$ & $11.28 \pm 6.11$ \\
& Fat $(\mathrm{g})$ & $2.89 \pm 10.45$ & $2.21 \pm 8.71$ & $2.45 \pm 13.10$ & $1.81 \pm 10.46$ \\
& Carbohydrates $(\mathrm{g})$ & $6.02 \pm 3.80$ & $4.46 \pm 2.42$ & $3.81 \pm 1.59$ & $4.01 \pm 10.55$ \\
& Calories $(\mathrm{Kcal})$ & $41.05 \pm 6.71$ & $39.82 \pm 6.42$ & $36.40 \pm 6.49$ & $31.10 \pm 7.55$ \\
& Calcium $(\mathrm{mg})$ & $4.74 \pm 1.69$ & $4.29 \pm 1.38$ & $4.35 \pm 1.28$ & $4.23 \pm 0.52$ \\
& Iron $(\mathrm{mg})$ & $5.92 \pm 5.38$ & $5.93 \pm 7.19$ & $5.01 \pm 1.38$ & $3.01 \pm 6.52$ \\
& Vitamin A $(\mu \mathrm{g})$ & $540.41 \pm 1240.13$ & $245.08 \pm 1182.71$ & $-3.81 \pm 1152.42$ & $41.52 \pm 651.13$ \\
& Vitamin B $(\mathrm{mg})$ & $0.71 \pm 0.49$ & $0.62 \pm 0.58$ & $0.31 \pm 0.52$ & $0.28 \pm 0.58$ \\
& Vitamin C $(\mathrm{mg})$ & $25.48 \pm 52.19$ & $8.28 \pm 62.52$ & $-3.39 \pm 61.71$ & $6.01 \pm 34.23$ \\
\hline
\end{tabular}

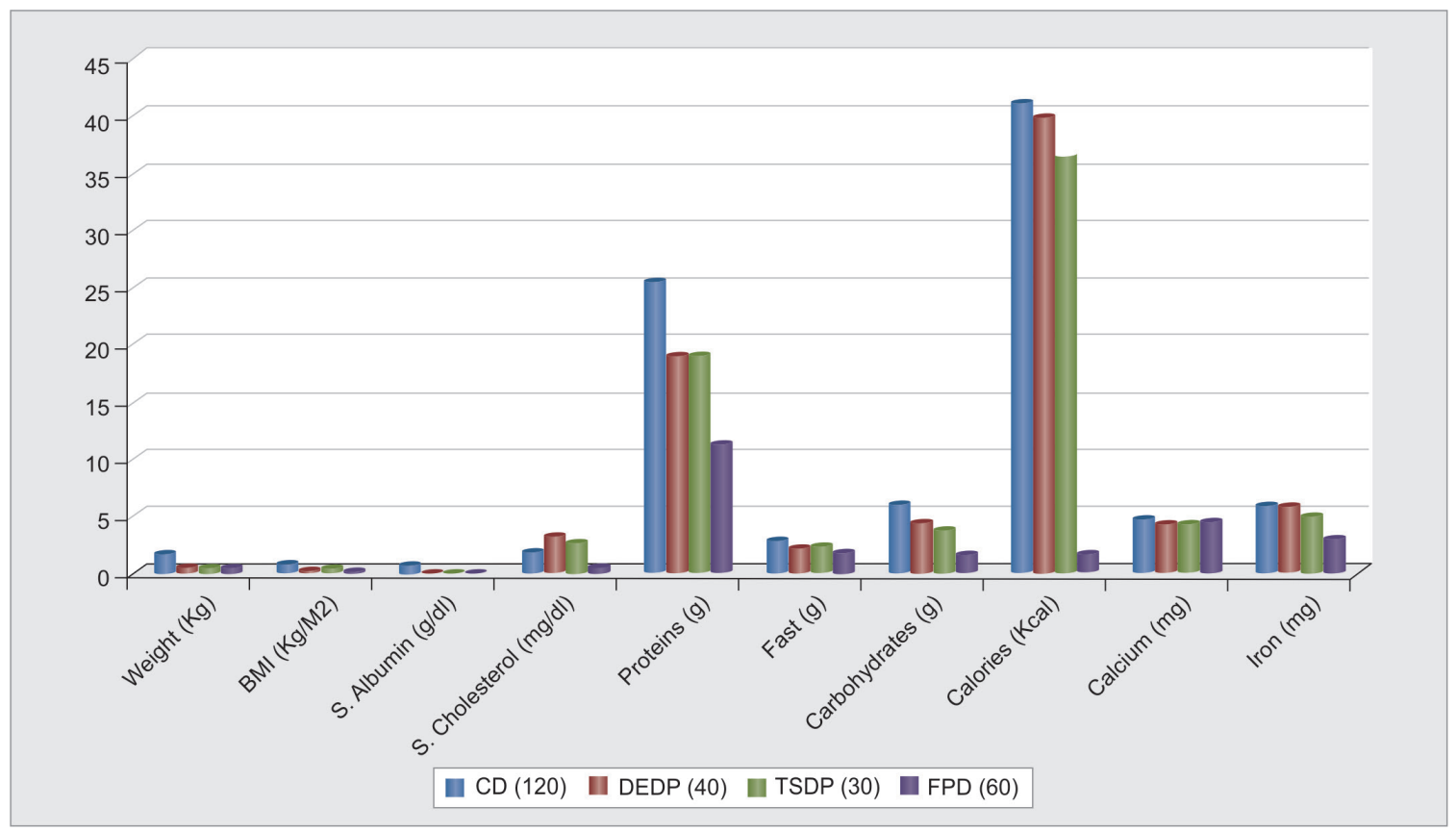

Graph 1: Mean change in variables from baseline to 5 months measured in different prosthetic groups

Table 3: Significance ( $p$ value) of mean change from baseline to 5 months measured in different prosthetic groups

\begin{tabular}{|c|c|c|c|c|c|c|c|c|c|}
\hline Comparison & & $\begin{array}{l}C D \text { vs } \\
D E D P\end{array}$ & $\begin{array}{l}C D \text { vs } \\
T S D P\end{array}$ & $\begin{array}{l}C D \text { vs } \\
F P D\end{array}$ & $\begin{array}{l}\text { DEDP vS } \\
T S D P\end{array}$ & $\begin{array}{l}\text { DEDP vs } \\
F P D\end{array}$ & $\begin{array}{l}\text { TSDP vS } \\
F P D\end{array}$ & $f$-value & $p$-value \\
\hline \multirow[t]{2}{*}{ Anthropometric variables } & Weight (kg) & 0.009 & 0.009 & 0.001 & 1.001 & 1.201 & 1.102 & 7.92 & 0.001 \\
\hline & BMI $\left(\mathrm{kg} / \mathrm{m}^{2}\right)$ & 0.006 & 0.012 & 0.003 & 0.855 & 0.910 & 0.210 & 8.12 & 0.002 \\
\hline \multirow[t]{2}{*}{ Biochemical variables } & Serum albumin (g/dl) & 0.785 & 0.859 & 0.685 & 1.112 & 1.112 & 1.202 & 0.53 & 0.523 \\
\hline & Serum cholesterol $(\mathrm{mg} / \mathrm{dl})$ & 0.895 & 0.782 & 0.813 & 0.842 & 0.420 & 0.320 & 0.58 & 0.741 \\
\hline \multirow[t]{9}{*}{ Nutrients } & Proteins (g) & 0.081 & 0.011 & 0.001 & 0.751 & 0.001 & 0.002 & 21.05 & 0.005 \\
\hline & Fat $(\mathrm{g})$ & 1.001 & 1.025 & 0.615 & 0.992 & 0.823 & 0.428 & 0.08 & 0.682 \\
\hline & Carbohydrates (g) & 0.865 & 0.235 & 0.023 & 0.248 & 0.139 & 0.271 & 4.12 & 0.010 \\
\hline & Calories (Kcal) & 0.485 & 0.074 & 0.001 & 0.468 & 0.965 & 0.312 & 8.12 & 0.018 \\
\hline & Calcium (mg) & 0.811 & 0.522 & 0.251 & 0.358 & 0.910 & 0.282 & 1.88 & 0.128 \\
\hline & Iron (mg) & 0.268 & 0.352 & 0.033 & 0.339 & 0.718 & 0.183 & 6.21 & 0.002 \\
\hline & Vitamin A $(\mu \mathrm{g})$ & 0.568 & 0.007 & 0.522 & 0.225 & 0.680 & 0.741 & 1.59 & 0.323 \\
\hline & Vitamin B (mg) & 0.874 & 0.315 & 0.001 & 0.184 & 0.760 & 0.775 & 0.6 .85 & 0.028 \\
\hline & Vitamin C (mg) & 0.672 & 0.029 & 0.522 & 0.920 & 0.810 & 0.682 & 1.81 & 0.230 \\
\hline
\end{tabular}


Assessment of various Nutritional Parameters in Geriatric Patients Who underwent different Prosthodontic Treatments

Table 4: Significance ( $p$ value) of mean change from baseline to 5 months measured in different groups categorized according to number of missing teeth

\begin{tabular}{lllllll}
\hline Comparison & & Group 1 vs 2 & Group 1 vs 3 & Group 2 vs 3 & $f$-value & $p$-value \\
\hline Anthropometric variables & Weight $(\mathrm{kg})$ & 0.845 & 0.4259 & 0.978 & 1.12 & 0.134 \\
& BMI $\left(\mathrm{kg} / \mathrm{m}^{2}\right)$ & 0.425 & 0.235 & 0.785 & 1.52 & 0.112 \\
Biochemical variables & Serum albumin $(\mathrm{g} / \mathrm{dl})$ & 0.747 & 0.363 & 0.777 & 0.28 & 0.784 \\
& Serum cholesterol $(\mathrm{mg} / \mathrm{dl})$ & 0.768 & 0.425 & 0.685 & 0.51 & 0.645 \\
Nutrients & Proteins $(\mathrm{g})$ & 0.231 & 0.225 & 0.845 & 4.71 & 0.001 \\
& Fat $(\mathrm{g})$ & 1.083 & 1.102 & 0.945 & 0.21 & 0.512 \\
& Carbohydrates $(\mathrm{g})$ & 0.128 & 0.236 & 0.152 & 1.39 & 0.512 \\
& Calories $(\mathrm{Kcal})$ & 0.211 & 0.525 & 0.715 & 0.61 & 0.134 \\
& Calcium $(\mathrm{mg})$ & 0.312 & 0.622 & 0.291 & 1.38 & 0.335 \\
& Iron $(\mathrm{mg})$ & 0.288 & 0.601 & 0.746 & 2.51 & 0.512 \\
& Vitamin A $(\mathrm{mg})$ & 0.098 & 0.402 & 0.666 & 0.61 & 0.412 \\
& Vitamin B $(\mathrm{mg})$ & 0.122 & 0.878 & 0.712 & 3.92 & 0.315 \\
& Vitamin C $(\mathrm{mg})$ & 0.312 & 0.836 & 0.839 & 0.29 & 0.520 \\
\hline
\end{tabular}

Table 5: Significance ( $p$ value) of mean change from baseline to 5 months measured in variables in completely and partially edentulous patients

\begin{tabular}{llllll}
\hline Comparison & & Complete denture & Partial denture $(R P D \pm F P D)$ & $t$-value & $p$-value \\
\hline Anthropometric variables & Weight $(\mathrm{kg})$ & $1.68 \pm 1.23$ & $0.51 \pm 1.31$ & 4.59 & 0.001 \\
& BMI $\left(\mathrm{kg} / \mathrm{m}^{2}\right)$ & $0.88 \pm 0.45$ & $0.17 \pm 0.39$ & 4.73 & 0.001 \\
Biochemical variables & Serum albumin $(\mathrm{g} / \mathrm{dl})$ & $0.71 \pm 0.35$ & $0.07 \pm 0.25$ & 1.47 & 0.784 \\
& Serum cholesterol $(\mathrm{mg} / \mathrm{dl})$ & $1.90 \pm 7.75$ & $1.95 \pm 8.61$ & 0.10 & 0.645 \\
Nutrients & Proteins $(\mathrm{g})$ & $25.43 \pm 6.12$ & $17.17 \pm 7.64$ & 5.15 & 0.001 \\
& Fat $(\mathrm{g})$ & $2.89 \pm 10.45$ & $2.51 \pm 11.51$ & 0.38 & 0.512 \\
& Carbohydrates $(\mathrm{g})$ & $6.02 \pm 3.80$ & $4.12 \pm 2.11$ & 3.31 & 0.003 \\
& Calories $(\mathrm{Kcal})$ & $41.05 \pm 6.71$ & $36.42 \pm 7.33$ & 3.27 & 0.004 \\
& Calcium $(\mathrm{mg})$ & $4.74 \pm 1.69$ & $4.48 \pm 1.71$ & 2.33 & 0.010 \\
& Iron $(\mathrm{mg})$ & $5.92 \pm 5.38$ & $3.71 \pm 5.76$ & 3.51 & 0.002 \\
& Vitamin A $(\mathrm{mg})$ & $540.41 \pm 1240.13$ & $91.43 \pm 1312.37$ & 1.46 & 0.072 \\
& Vitamin B $(\mathrm{mg})$ & $0.71 \pm 0.49$ & $0.40 \pm 0.53$ & 3.82 & 0.003 \\
& Vitamin C $(\mathrm{mg})$ & $25.48 \pm 52.19$ & $5.28 \pm 54.76$ & 0.031 \\
\hline
\end{tabular}

Table 6: Significance ( $p$ value) of mean change from baseline to 5 months measured in variables in removable prosthesis vs fixed prosthesis

\begin{tabular}{|c|c|c|c|c|c|}
\hline Comparison & & $\begin{array}{l}\text { Removable } \\
(C D \pm D E D P \pm T S D P)\end{array}$ & Fixed prosthesis & $t$-value & $p$-value \\
\hline \multirow[t]{2}{*}{ Anthropometric variables } & Weight (kg) & $1.29 \pm 1.45$ & $0.41 \pm 1.19$ & 2.84 & 0.017 \\
\hline & $\mathrm{BMI}\left(\mathrm{kg} / \mathrm{m}^{2}\right)$ & $0.51 \pm 0.62$ & $0.21 \pm 0.51$ & 2.95 & 0.003 \\
\hline \multirow[t]{2}{*}{ Biochemical variables } & Serum albumin $(g / d l)$ & $0.38 \pm 3.41$ & $0.09 \pm 0.41$ & 0.88 & 0.452 \\
\hline & Serum cholesterol (mg/dl) & $2.82 \pm 7.65$ & $0.52 \pm 11.31$ & 1.01 & 0.528 \\
\hline \multirow{9}{*}{ Nutrients } & Proteins (g) & $24.42 \pm 7.16$ & $11.28 \pm 6.11$ & 5.15 & 0.001 \\
\hline & Fat $(g)$ & $2.15 \pm 11.23$ & $1.81 \pm 10.46$ & 0.38 & 0.681 \\
\hline & Carbohydrates (g) & $4.81 \pm 3.96$ & $4.01 \pm 10.55$ & 3.31 & 0.049 \\
\hline & Calories (Kcal) & $39.21 \pm 7.18$ & $31.10 \pm 7.55$ & 3.27 & 0.003 \\
\hline & Calcium (mg) & $4.81 \pm 1.43$ & $4.23 \pm 0.52$ & 2.33 & 0.214 \\
\hline & Iron (mg) & $6.02 \pm 4.71$ & $3.01 \pm 6.52$ & 3.51 & 0.048 \\
\hline & Vitamin $A(\mu g)$ & $321.19 \pm 986.24$ & $41.52 \pm 651.13$ & 1.46 & 0.315 \\
\hline & Vitamin B (mg) & $0.61 \pm 0.50$ & $0.28 \pm 0.58$ & 3.82 & 0.002 \\
\hline & Vitamin C (mg) & $14.58 \pm 60.86$ & $6.01 \pm 34.23$ & 2.62 & 0.281 \\
\hline
\end{tabular}

\section{DISCUSSION}

Evidences from the literature indicate that nutritional status of a person is a multifactorial parameter. Apart from socioeconomic class, income levels, and other social parameters, dental status might play a crucial role in its development. ${ }^{18}$ In geriatric patients, balanced nutrition is necessary for the oral health and comfort to increase the longevity and success of prosthodontic treatment. ${ }^{19}$ Hence, we assessed various nutritional parameters in geriatric patients who underwent different prosthodontic treatments. While comparing the mean change in the nutritional parameters in the patients who underwent 
different treatment modalities, we observed significant improvement in body weight and BMI in the group of patients who received CD compared with patients who received RPD and FPD, as shown in Table 3. Kanehisa et $\mathrm{al}^{16}$ observed similar results in their study, in which they found significant increase in mean body weight between denture wearers and nonwearers. The possible reason for this increase in mean body weight may be because of the improvement in mastication due to denture wearing and increased comminution and nutrient absorption from gastrointestinal tract. ${ }^{19}$ At the same time, contrasting results were obtained by Sahyoun et $\mathrm{al}^{20}{ }^{20}$ who found elevated BMI in edentulous patients compared with denture wearers. According to them, this might be due to increase in consumption of rich calories of food by edentulous patients, which subsequently resulted in increase in BMI of the body. We also observed a nonsignificant increase in the values of serum albumin in patients who received prosthodontic treatment. Our results were in correlation with the results obtained by Kanehisa et $\mathrm{al}^{16}$ who also observed an increase in serum albumin values in denture users.

We also found an increase in intake of nutritional values in patients having $C D$ compared with patients using RPD or FPD, as shown in Table 5. Similar results were obtained by Krall et $\mathrm{al}^{21}$ who, from their study, concluded that patients with RPDs had similar nutritional intake values when compared with persons with intact dentition status. Furthermore, they also reported better nutritional consumption values for these persons compared with patients with missing teeth who hadn't undergone prosthetic rehabilitation and in persons who wore CDs. From these results, we also noticed a significant increase in consumption of proteins in patients who wore CD compared with patients wearing RPDs and FPDs. As stated by Goel et al $^{19}$ this may be due to an increase in intake of softer carbohydrate-rich and low-protein diet by CD wearers. While comparing the mean calcium intake by the patients, all the groups showed a significant increase in the mean values of the calcium. Our results were in correlation with the results of Sheiham et al, ${ }^{22}$ who also observed significant increase in calcium intake on denture wearers. We did not observe any significant increase in mean vitamin A and C uptake values in different denture wearer groups. This might be due to significance increase in uptake of fruits, vegetables, and salads after prosthetic rehabilitation. ${ }^{23}$ While comparing the mean body weight, BMI, calories, calcium, iron, and vitamin B, a statistically significant increase in value was seen in patients wearing removable dentures compared with patients wearing fixed dentures. As stated by Tsai and Chang, ${ }^{24}$ poorer masticatory ability in nondenture wearers and removable denture wearers might predispose them to greater nutritional risk compared with patients wearing FPDs. McKenna et $\mathrm{al}^{25}$ investigated the impact of tooth replacement on the nutritional status of partially dentate older patients and concluded that prosthodontic rehabilitation may play an important role in the nutritional status of partially dentate elders.

\section{CONCLUSION}

From the results, we conclude that both nutrition and diet form an integral part of the prosthodontic treatment in maintaining the health of the body among elderly population. Further studies with higher study groups and more number of parameters are required to explore the treatment modalities available for geriatric patients.

\section{REFERENCES}

1. McKenna G, Allen PF, O'Mahony D, DaMata C, Cronin M, Woods $\mathrm{N}$. The importance of oral health for the systemic well being of an ageing population. Ir Med J 2009 Jul-Aug;102(7): 202-204.

2. Jin LJ, Chiu GK, Corbett EF. Are periodontal diseases risk factors for certain systemic disorders - What matters to medical practitioners? Hong Kong Med J 2003 Feb;9(1):31-37.

3. Seymour RA. Does periodontal treatment improve general health? Dent Update 2010 May;37(4):206-212.

4. Lee JS, Weyant RJ, Corby P, Kritchevsky SB, Harris TB, Rooks R, Rubin SM, Newman AB. Edentulism and nutritional status in a biracial sample of well-functioning, community dwelling elderly: the health, aging, and body composition study. Am J Clin Nutr 2004 Feb;79(2):295-302.

5. Bryant SR, Zarb GA. Outcomes of implant prosthodontic treatment in older adults. J Can Dent Assoc 2002 Feb;68(2):97-102.

6. Palmer CA. Gerodontic nutrition and dietary counseling for prosthodontic patients. Den Clin North Am 2003 Apr;47(2): 355-371.

7. Shah N, Parkash H, Sunderam KR. Edentulousness, denture wear and denture needs of Indian elderly - A communitybased study. J Oral Rehabil 2004 May;31(5):467-476.

8. Planning Commission Further Lowers Poverty Line to Rs. 28/ Day. India Today, March 19, 2012. New Delhi, India. Accessed June 13, 2014. Available from: http://indiatoday.intoday. in/story/indiapoverty-line-now-lowered-to-rs-28-per-day / 1/178483.html.

9. Diagnostic and statistical manual of mental disorders. 4th ed. Washington (DC): American Psychiatric Association; 2000.

10. DSM-IV Criteria for Alcohol Abuse and Alcohol Dependence. Reference for the wholesection. Accessed June 13,2014. Available from: http:/ / www.alcoholcostcalculator.org/business / about/dsm.html.

11. Seman K, Manaf HA, Ismail AR. Association between functional dentition with inadequate calorie intake and underweight in elderly people living in "Pondok" in Kelantan. Arch Orofac Sci 2007 Sep;2:10-19.

12. Lamster IB. Oral health care services for older adults: A looming crisis. J Am Public Health 2004 May;94(5):699-702.

13. Walton JC, Miller J, Tordecilla L. Elder oral assessment and care. Med Surg Nursing 2001 Feb;10(1):37-44. 
14. Brodeur JM, Laurine D, Vallee R, Lachapelle D. Nutrient intake and gastrointestinal disorders related to masticatory performance in the edentulous elderly. J Prosthet Dent 1993 Nov;70(5):468-473.

15. Papas AS, Palmer CA, Rounds MC, Herman J, McGandy RB, Hartz SC, Russell RM, DePaola P. Longitudinal relationships between nutrition and oral health. Ann NY Acad Sci 1989;561: 124-142.

16. Kanehisa $Y$, Yoshida M, Taji T, Akagawa Y, Nakamura H. Body weight and serum albumin change after prosthodontic treatment among institutionalized elderly in a long-term care geriatric hospital. Community Dent Oral Epidemiol 2009 Dec;37(6):534-538.

17. Wostmann B, Michel K, Brinkert B, Melchheier-Weskott A, Rehmann P, Balkenhol M. Influence of denture improvement on the nutritional status and quality of life of geriatric patients. J Dent 2008 Oct;36(10):816-821.

18. Steen B. Preventive nutrition in old age - A review. J Nutr Health Aging 2000;4(2)114-119.

19. GoelK,SinghSV,Chand P,RaoJ, TripathiS, Kumar L, MahdiAA, Singh K. Impact of different prosthodontic treatment modalities on nutritional parameters of elderly patients. J Prosthodont 2016 Jan;25(1):21-27.

20. Sahyoun NR, Lin CL, Krall E. Nutritional status of the older adult is associated with dentition status. J Am Diet Assoc 2003 Jan;103(1):61-66.

21. Krall E, Hayes C, Garcia R. How dentition status and masticatory function affect nutrient intake. J Am Dent Assoc 1998 Sep;129(9):1261-1269.

22. Sheiham A, Steele JG, Marcenes W, Lowe C, Finch S, Bates CJ, Prentice A, Walls AW. The relationship among dental status, nutrient intake, and nutritional status in older people. J Dent Res 2001 Feb;80(2):408-413.

23. Greksa LP, Parraga IM, Clark CA. The dietary adequacy of edentulous older adults. J Prosthet Dent 1995 Feb;73(2):142-145.

24. Tsai AC, Chang TL. Association of dental prosthetic condition with food consumption and the risk of malnutrition and follow-up 4-year mortality risk in elderly Taiwanese. J Nutr Health Aging 2011 Apr;15(4):265-270.

25. McKenna G, Allen PF, Flynn A, O'Mahony D, DaMata C, Cronin M, Woods N. Impact of tooth replacement strategies on the nutritional status of partially-dentate elders. Clin Oral Investig 2015 Nov;19(8):1991-1998. 